\title{
Self and other
}

\section{From pure ego to co-constituted we}

\section{Zahavi, Dan}

Published in:

Continental Philosophy Review

DOI:

10.1007/s11007-015-9328-2

Publication date:

2015

Document version

Early version, also known as pre-print

Citation for published version (APA):

Zahavi, D. (2015). Self and other: From pure ego to co-constituted we. Continental Philosophy Review, 48(2), 143-160. https://doi.org/10.1007/s11007-015-9328-2 


\section{Forthcoming in Continental Philosophy Review. Please quote from published version.}

\section{Self and Other: From pure ego to co-constituted we}

In an article from 1995, Meltzoff and Moore distanced themselves from two historically influential views on the status of the self in infancy. According to the first, that of Piaget, the infant lives in an adualistic universe at birth and only comes to discover the existence of others as separate entities at a relatively late developmental stage. According to the second, that of social constructivism, infants are initially selfless and only come to acquire selfhood through social interaction (Meltzoff \& Moore 1995: 88). As Meltzoff and Moore argue, we ought to reject both views in favor of the following alternative:

The newborn brings innate structure to his or her first interactions with people, and yet interactions with other individuals profoundly alter the notion of self. The challenge for a theory of selfdevelopment is to specify this innate structure and the way that it is subsequently reorganized. A theory of development that mischaracterizes the newborn is flawed; a model of the innate that ignores development misses the human capacity for reconceiving things, even our self (Meltzoff \& Moore 1995: 88).

In the following, I will offer a phenomenological defense of the view that selfhood is both innate and transformed through social interaction. This defense will draw on material from my book Self and Other: Exploring Subjectivity, Empathy and Shame (2014) and at the same time present its main line of argumentation.

\section{Experiential minimalism and social constructivism}

It is not hard to find philosophers who deny the existence of the self. One forceful expression of such skepticism can be found in Metzinger's book, Being No One, from 2003. As Metzinger writes, "no such things as selves exist in the world. Nobody ever was or had a self" (2003: 1). In order to assess the cogency of Metzinger's anti-realism, it is important to know what exactly it is that he takes himself to be denying. What is a self? For Metzinger, the self can be defined as an ontologically self-subsistent entity, i.e., as something that in principle could exist all by itself (2003: 626, 2011: 280). Since he denies the existence of such an entity, he considers the self to be illusory, and insists that rigorous philosophical analysis of and scientific research on the self must be protected from the degenerate debates found in philosophical phenomenology (Metzinger 2011: 294).

Metzinger does admit that the no-self view comes in a variety of different flavors and strengths (Metzinger 2011: 293), but he unfortunately fails to realize that the same holds true for the no-no-self alternative. To put it differently, Metzinger's skeptical conclusion would only be warranted if his 
definition of the self were the only one available, but that is hardly the case. Quite the contrary, in fact, since the notion he employs is one that has largely been abandoned, not only by most of the empirical researchers who these days investigate the development, structure, function and pathology of self, but also by most philosophers steeped in twentieth-century German and French philosophy. Rather than saying that the self does not exist, I think Metzinger should have settled for a far more modest claim. He should have qualified his statement and instead denied the existence of a quite specific kind of self, namely the self understood as an unchanging and imperishable soul-substance. One might then add that, if this is indeed his conclusion, it is somewhat less provocative than he himself seems to think.

But what might be relevant alternatives? Let me in the following contrast two different accounts of the self that we can call experiential minimalism and social constructivism.

According to the first, experientialist, approach, selfhood is a built-in feature of our experiential life. More specifically, it has been suggested that phenomenally conscious episodes, episodes characterized by a subjective what-it-is-likeness, are not merely episodes that happen to take place in a subject, regardless of whether or not the subject is aware of it. Rather, such episodes are necessarily prereflectively self-conscious in the weak sense that they are like something for the subject. Indeed, for every possible experience we might have, each of us can say that regardless of whatever it is like for me to have this experience: it is for me that it is like that to have the experience. To that extent, what-it-islike-ness is properly speaking what-it-is-like-for-me-ness. This for-me-ness does not denote a specific experiential content; rather, it refers to the first-personal presence of experience. It refers to the fact that the experiences I am living through present themselves differently to me than to anybody else. When I have experiences, I have them minely, so to speak. The claim is, then, that this first-personal presence, this for-me-ness, amounts to a primitive and minimal form of selfhood. As Sartre puts it, "pre-reflective consciousness is self-consciousness. It is this same notion of self which must be studied, for it defines the very being of consciousness" (Sartre 2003: 100). Importantly, this experiential self is not something that exists independently of, in separation from, or in opposition to the stream of consciousness, but is rather to be considered an integral part of experiential life.

According to the second approach, we need to distinguish between merely being conscious or sentient, and being a self. The requirements that must be met to qualify for the latter are higher. Being a self is an achievement rather than a given, and therefore something one can fail at. A self is not born, it is not something innate, but rather something that emerges in a process of social experience and interchange. Thus, one cannot be a self on one's own, but only together with others. Indeed, on this account, the self is best described as a social construction, something that is more a matter of politics and culture, than of science and nature. On one particular version of this approach, to be a self is to stand in a particular interpretative and evaluative relation to oneself, and the only way to obtain the reflexive selfrelation constitutive of selfhood is by being socialized into a publicly shared space of normativity. On another version of the approach, we weave stories of our lives, we organize and unify our experiences and actions according to narrative structures, and the claim has been that this is what constitutes us as persisting selves. 
Importantly, despite their obvious differences, both of these approaches would reject the definition of self espoused by anti-realists like Metzinger, that is, they would both reject the view that the self - if it exists - must be an unchanging and ontologically independent entity. Of course, this does not prove that the two accounts are viable accounts. The first in particular, which has a distinct phenomenological ancestry, and can count Husserl, Sartre and Henry among its defenders (see, for instance, Husserl 1973b: 351, Sartre 2003: 100, Henry 1963: 581, Zahavi 2005, 2009), has recently been met with a number of objections.

According to one objection, prior to reflection, consciousness is so fully immersed in the world that it remains oblivious to itself. There is at that stage and on that level no room for self-consciousness, forme-ness or mineness. On such a reading, experiential ownership is the outcome of a meta-cognitive operation that involves conceptual and linguistic resources. According to another, even more radical, objection, phenomenal consciousness is strictly and exclusively world-presenting. By being aware of external objects, we might indirectly become aware that we are having certain experiences, but we are never directly aware of the experiences themselves, not even when we reflect upon them or introspect. One difficulty faced by the former objection is that it has to either deny phenomenal consciousness to pre-linguistic creatures, such as non-human animals and infants, or show that phenomenally conscious episodes can lack first-personal givenness and experiential perspectivalness altogether, i.e., show that they fail to present themselves to the subject of those episodes in a manner that is in principle unavailable to others. The position consequently has to claim that, in the case of pre-linguistic creatures, they either have no experiences, or whatever experiences they have are present to them in a third-person manner, that is, in the same way as publicly available objects are. The second objection is confronted with a related challenge. It argues that conscious mental states are states we are conscious with and not states we are conscious of (Dretske 1995: 100-101), that is, that phenomenal consciousness presents us with nothing except for external objects and their properties. It is unclear, however, to what extent such a view really allows us to distinguish conscious and non-conscious mental states, all of which allegedly represent objects in the environment. It is surely no coincidence that Dretske ends up denying that we have any direct access to the fact that we are conscious rather than non-conscious and therefore concludes that we cannot know, at least not in any direct manner, that we are not zombies (Dretske 2003: 8). I cannot unwrap and develop this criticism in any further detail here (see Zahavi 2014), but I consider the conclusions that both objections end up with to be so counter-intuitive that they might serve as a reductio ad absurdum of the premises of such objections or at the very least motivate us to look for more plausible alternatives.

Experiential minimalism faces other challenges, however. One important reservation is the following. Rather than denying experiential subjectivity outright, one might simply reject the attempt to identify the latter with some kind of self, and instead insist on the need for a distinction between subjectivity and selfhood. It should not come as a surprise that one version of this objection has precisely been raised by advocates of the more normatively oriented approach to self. On Taylor's account, for instance, experiential subjectivity has no relevance for and can safely be ignored by a theory of the self (Taylor 1989: 49). Who we are is not constituted by intrinsic features of experience, but by our normative 
commitments and endorsements. Rather than simply being a brute fact, rather than simply being something waiting to be discovered, who we are is a question of our self-interpretation, of who we take ourselves to be. Although, I would agree that an exhaustive account of human selfhood certainly does need to include a consideration of the role played by our ongoing self-interpretation and must consider the extent to which our self-identity is constituted by our choices and actions (Korsgaard 2009: 43), I would dispute the assertion that any such normative account can stand on its own. It necessarily presupposes the dimension of selfhood that is targeted by the experience-based approach or, to put it differently, experiential ownership is a pre-reflective and pre-linguistic presupposition for all normative commitments and narrative self-interpretations. During the last few years, this point seems to have been accepted by at least some narrativists, since they now explicitly concede that any plausible account of selfhood must respect the importance of the first-personal character or subjectivity of experience (Schechtman 2011, Rudd 2012). However, they would typically maintain that it remains necessary to distinguish subjectivity from selfhood. The former is only a necessary and not a sufficient condition for the latter. As long as both parties agree that our experiential life is as such and from the beginning characterized by pre-reflective self-consciousness and by its first-personal character and for-me-ness, the dispute seems primarily terminological. It concerns the question of whether it is better to distinguish between subjecthood and selfhood rather than between different levels or aspects of selfhood. Nothing decisive hangs on this terminological choice, though my own preference is for the latter. I do not merely think that this choice is systematically defensible and has historical precedence. I also think the continuing reference to a level of experiential selfhood will help to remind us of the proper significance of the experiential features in question.

What should be clear, however, is that, rather than seeing the two outlined notions of the self as alternatives that we have to choose between, it might be better to see them as complementary notions that each capture something central and important. Indeed, we should not accept being forced to choose between viewing selfhood as either a socially constructed achievement or an innate and culturally invariant as a given. Who we are is both made and found. Why is there no incompatibility or straightforward contradiction involved in embracing both views? Obviously, because they target different aspects or levels of selfhood, and the minimalist notion of an experiential self is fully compatible with a more complex notion of a socially and normatively embedded self. What at first sight looked like a substantial disagreement might in the end be more of a terminological dispute that can be resolved the moment we discard the ambition of operating with only one notion of selfhood.

Having said this, it would obviously be naive to imagine that every disagreement will automatically dissolve the moment one recognizes the need for a distinction between different notions or levels of selfhood. There are still forms of social constructivism that remain incompatible with experiential minimalism. Consider as an illustration Husserl's writings on the pure ego in Ideas II. As I read Husserl, his introduction of the pure ego is an attempt to do justice to the first-personal character of consciousness; it is an attempt to point to the intrinsic and "absolute individuation" of consciousness (cf. Husserl 1952: 97), an individuation that the subject precisely does not first acquire through a confrontation and interaction with others. According to Husserl, it is consequently quite legitimate to 
conduct a formal analysis of the relation between selfhood, pre-reflective self-consciousness, and the structures of the stream of consciousness without introducing others into the analysis. As he writes, when it comes to the peculiar mineness (Meinheit) of experiential life, this is an aspect that can be characterized without any contrasting others (Husserl 1973b: 351). But, as Husserl also points out, the pure ego contains no hidden inner richness; rather than being something mysterious or secret, it is simply the name for the subject of experience (Husserl 1952: 97). It is pure in the sense of being formal, and consequently poor in terms of content (Husserl 1976: 179). Compare this line of reasoning with the position of Wolfgang Prinz, who argues that the "social construction of subjectivity and selfhood relies on, and is maintained in, various discourses on subjectivity" (Prinz 2003: 515). Prinz consequently distances himself from the naturalist idea that a self is a natural entity and instead holds the view that it depends on the social and cultural resources on which and from which it is built (Prinz 2012: 35, 182). What is remarkable about Prinz's proposal is that he explicitly defines the notion of self in terms of "me-ness" (Prinz 2003: 517), i.e., the notion of self that he considers to be a social construct is very akin to the experiential self that $I$ have been articulating in the preceding. As a consequence, the position defended by Prinz is quite radical, since he claims that human beings who were denied all socially mediated attributions of self - like, say, the famous case of Kasper Hauser - would be "completely self-less and thus without consciousness" and would therefore remain "unconscious zombies" (Prinz 2003: 526). Prinz is right to insist that a thorough social constructivism regarding selfhood must also defend the socially constructed character of phenomenal consciousness, and he clearly illustrates the (absurd) implications of such a view.

\section{Empathy and other-directed intentionality}

As should be clear by now, my criticism not only targets the no-self account, but also the kind of social constructivism that argues that the self is socially constructed through and through, and that all selfexperience is intersubjectively mediated. I am not disputing that we de facto live together with others in a public world from the very start, but I would deny that the very mineness or for-me-ness of experience is constitutively dependent upon social interaction. In short, I am not disputing the de facto co-existence and co-emergence of experiential selfhood and intersubjectivity, but am rather denying their constitutive interdependence. As briefly indicated above, this view is in many ways Husserlian. But shouldn't this make us pause? Isn't phenomenology and in particular Husserlian phenomenology faced with notorious problems when it comes to the issue of intersubjectivity? Over the years, the notion of an experiential self has encountered some resistance. I think one reason for this opposition has been the worry that, if one takes the reflexivity that constitutes basic selfhood to be a built-in feature of the individual mind, one that is not constitutively dependent upon one's relation to others, then one either directly or in a more oblique manner commits oneself to a form of Cartesianism, where the essence of selfhood is taken to be some kind of self-enclosed solitary interiority (Maclaren 2008).

I would dispute this. I don't think a focus on phenomenal consciousness and an appreciation of the fact that we are first-personally acquainted with our own experiential life must go hand in hand with the 
view that the experiences of others are not manifest or present or given in any straightforward sense to us, and that second- and third-person ascriptions of mental states are consequently highly indirect, highly inferential endeavors. In fact, I think it would be quite unfortunate if the long overdue recognition of the importance of subjectivity and the first-personal character of consciousness were to go hand in hand with a commitment to an inferentialist account of intersubjectivity, according to which our ascription of a mental life to others is based on an inference to the best explanation. Let me in the following try to show that there is no conflict between defending the notion of an experiential self and arguing that we can be experientially acquainted with the subjectivity of others. In fact, rather than preventing a satisfactory solution to the problem of other minds, I would consider the notion of an experiential self a precondition for any plausible account of intersubjectivity.

Roughly 100 years ago, during the second decade of the $20^{\text {th }}$ century, a number of phenomenologists such as Husserl, Stein, Scheler and Walther were engaged in intense discussions about how best to analyze and characterize the nature and structure of empathy (see Zahavi 2010, 2011, 2012). Thus, contrary to Dennett's repeated characterization of classical phenomenology as an autophenomenology, i.e., as a phenomenology with no interest in the mental life of others (Dennett 1987: 153-154), classical phenomenology did very much engage in heterophenomenology. Indeed, one reason why the phenomenological analysis of empathy is of interest in this context is precisely because - while remaining firmly committed to the first-personal character of consciousness - it highlights and respects what is distinctive about the givenness of others.

Although the phenomenologists mentioned above did not agree on everything, they were united in their rejection of attempts to explain empathy in terms of mirroring, mimicry, imitation or projection. Reacting, for instance, to Lipps' suggestion that empathy can be explained as a form of inner imitation, phenomenologists insisted that even if an observed expression might cause the empathizer to imitate it, and even if as a result of the close link between expression and experience, the observer subsequently came to experience the associated emotion herself, this would only explain why a certain experience occurred in the empathizer. It would not explain how the empathizer came to understand the other. For someone to have a feeling herself and for someone to empathically understand that another has a feeling are two quite different things. The former event does not per se entail either knowledge about the origin of the feeling, or knowledge about the similarity between one's own feeling and that of the other. In fact, it doesn't in and of itself lead to an understanding of the mental life of the other at all (cf. Gurwitsch 1979: 24-25, Stein 1989: 21-24). If presented with a currently popular proposal, namely, that empathy involves a simulation-plus-projection routine, the above-mentioned phenomenologists would have argued that such an account conflates empathy with other kinds of interpersonal understanding and ultimately, due to a misbegotten Cartesian heritage, disregards the fact that we can and do experience other minds. To quote Husserl:

Empathy is not a mediate experience in the sense that the other would be experienced as a psychophysical annex to his corporeal body but is instead an immediate experience of the other (Husserl 1952: 375, translation modified). 
Just as what is past can be originally given as past only through memory, and what is to come in the future can as such only be originally given through expectation, the foreign can only be originally given as foreign through empathy. Original givenness in this sense is the same as experience (Husserl 1959: 176).

It would be countersensical to say that it [foreign subjectivity] is inferred and not experienced when given in this original form of empathic presentation. For every hypothesis concerning a foreign subject already presupposes the 'perception' of this subject as foreign, and empathy is precisely this perception (Husserl 1973a: 352).

For phenomenologists, empathy is the label for our basic, perceptually-based understanding of others. It denotes our general ability to access the mental life of others in their expressions, expressive behavior and meaningful actions, and is what more complex and indirect forms of social cognition rely on and presuppose. Empathy is the experience of the embodied mind of the other, an experience which, rather than eliminating the difference between self-experience and other-experience, takes the asymmetry to be a necessary and persisting existential fact. Thus, phenomenologists would strongly oppose recent claims to the effect that empathic arousal blurs the distinction between self and other, that the other comes to feel like a part of our self, and that it leads to sense of merged personal identities (Cialdini et al 1997). Whereas the experience of empathizing is first-personally given, the empathized experience is not given first-personally to the empathizer. To insist that it is, is to miss what is special about empathy, namely the fact that it is a distinct form of other-directed intentionality. In short, empathy is what allows me to experience other experiencing subjects. It entails neither that the other's experience is literally transmitted to me, nor that I undergo the experience I observe in the other. Rather, to empathically experience, say, the emotion of another necessarily differs from the way you would experience the emotion if it were your own. The empathized experiences are necessarily given as belonging to another; they are given as lived through first-personally by that other; they are given as surpassing my apprehension (Husserl 1950: 144, 1973b: 631).

Although I do not have access to the first-personal character of the other's experience, although I do not experience it as it is experienced by the other, this does not make my understanding of the other non-experiential. To demand more, to claim that I would only have a real experience of the other if I experienced her feelings or thoughts in the same way as she herself does, is nonsensical, and fails to respect what is distinct and unique about the givenness of the other. In fact, one reason why phenomenologists were so strongly opposed to the attempt to explain empathy and other-understanding on the basis of some kind of projective account is that such an attempt would fail to do justice to the genuine and true self-transcendence that we find in empathy. As Husserl puts it, in empathy, consciousness transcends itself and is confronted with otherness of an entirely new kind (Husserl 1973a: 8-9, 442, see also Scheler 2008: 46, 49). 
One might consequently say that, for phenomenologists, empathy provides a special kind of knowledge by acquaintance. It is not the standard first-person acquaintance, but rather a distinct otheracquaintance. When saying that empathy can provide a special kind of understanding, this is not meant to suggest that empathy provides an especially profound or deep kind of understanding. In order to obtain that, theoretical inferences and imaginative simulations might very well be needed. No, the distinctiveness of the understanding is due to its basic and intuitive character: The other's empathized experience is given directly to me as present here and now. Just as we ought to respect the difference between thinking about a lion, imagining a lion, and seeing a lion, we also ought to respect the difference between referring to Emil's compassion or sadness, imagining in detail what it must be like for him to be compassionate or sad, and being empathically acquainted with his compassion or sadness in the direct face-to-face encounter. In the latter case, our acquaintance with Emil's experiential life has a directness and immediacy to it that is not shared by whatever beliefs I might have about him in his absence.

Some have claimed that the only way to solve the problem of intersubjectivity and avoid a threatening step towards solipsism is by conceiving of the difference between self and other as a founded and derived difference, a difference arising out of undifferentiated anonymous life. However, such a 'solution' does not solve the problem of intersubjectivity: it dissolves it. To speak of a fundamental anonymity prior to any distinction between self and other obscures that which has to be clarified, namely intersubjectivity understood as the relation between subjects. On the level of such fundamental anonymity, there is neither individuation nor selfhood, but there is also no differentiation, otherness, or transcendence, meaning that there is consequently no room for either subjectivity or intersubjectivity. To put it differently, any claim regarding a fundamental level of undifferentiation does not only threaten the notion of a self-given subject, but also the notion of an irreducible other. This is, of course, why I think that rather than impeding a satisfactory account of intersubjectivity, an emphasis on the inherent and essential individuation of experiential life must be seen as a prerequisite for getting the relation and difference between self and other right.

For phenomenologists, empathy presupposes an experiential distinction between self and other; it entails a preservation rather than an overcoming or elimination of the self-other differentiation. A basic presupposition in this line of reasoning is a commitment to an egological account of consciousness. The reason why the other is characterized by a certain dimension of transcendence, the reason why the other is an other, is precisely because he or she is also an experiential self, with his or her own irreplaceable first-person perspective. This is why any resolutely non-egological account of consciousness, and this would obviously include various Buddhist no-self accounts, must be faulted for its incapacity to convincingly account for empathy (and, by extension, compassion).

Compare, by way of illustration, the two following statements:

An enlightened being is strictly impartial, showing equal love and compassion for all sentient beings. But how can we make sense of this if there is a deep difference-if only an experiential one-between my suffering and yours? How can I view someone's suffering as just someone's suffering, rather than as my suffering or yours, if, in fact, there is a deep difference between us? 
To make sense of this, we must suppose that as an enlightened being, I would no longer conceive of someone as 'me' in a deep sense. I would no longer experience myself as myself but as an anonymous 'someone' (Fink 2012: 295).

Hence sympathy does not proclaim the essential identity of persons, as Schopenhauer and von Hartmann allege, but actually presupposes a pure essential difference between them [...]. [I]f, as we saw, it is the very office of true sympathy to dissipate the solipsistic illusion by apprehending the equivalent status of the other person as such, it cannot be at the same time a dim perception of the fact that neither of us really exists, but only some third party, of whom we are merely the functions (Scheler 2008: 65-66, translation modified).

It should be clear from the preceding why I would side with Scheler on this point. The connection between selfhood and empathy - and a nice formulation of a core tenet in the phenomenological account of the latter - can be found in another quote from Scheler, which incidentally is one that Husserl and Stein could both accept without any qualms:

That we cannot be aware of an experience without being aware of a self is something which is directly based upon the intuitable intrinsic connection between individual and experience [...]. It is a corollary of this that the other person has - like ourselves - a sphere of absolute personal privacy, which can never be given to us. But that 'experiences' occur there is given for us in expressive phenomena - again, not by inference, but directly, as a sort of primary 'perception'. It is in the blush that we perceive shame, in the laughter joy. To say that 'our only initial datum is the body' is completely erroneous. This is true only for the doctor or the scientist, i.e. for man in so far as he abstracts artificially from the expressive phenomena, which have an altogether primary givenness (Scheler 2008: 9-10).

Such a view is not unique to philosophers from the phenomenological tradition, but can also be found in the works of other thinkers of that time. In Philosophie der symbolischen Formen, for instance, Cassirer defends the view that the understanding of expressive phenomena is primitive and that it is more basic than the understanding of sensory phenomena or knowledge of proper objects. According to Cassirer, one of Scheler's great achievements was to have shown the phenomenological weaknesses of both the argument from analogy as well as Lipps' theory of projective empathy. Both approaches failed to appreciate that the expressive dimension is a genuinely original phenomenon. But to miss out on this is to close off all access to the world of inner experience; it is, as Cassirer puts it, to cut the bridge that alone could lead us into the realm of the thou (Cassirer 1957: 63, 65).

The focus on expressivity and empathy is, however, not entirely uncontroversial within phenomenology. Reservations can be found, for instance, in Heidegger and Gurwitsch who both argue that such a focus misconstrues the nature of intersubjectivity. It takes intersubjectivity to first and foremost be a thematic encounter between individuals, where one is trying to grasp the inner emotions 
or experiences of the other (this connotation is particularly evident in the German term Einfühlung) (Heidegger 2001: 145, Gurwitsch 1979: 104, 108, 112). It is not entirely clear, however, why Heidegger's and Gurwitsch's own emphasis on the worldly and cultural contextuality of intersubjective understanding should be incompatible with an emphasis on the importance of the face-to-face encounter. Moreover, the phenomenologists who did work on empathy did not conceive of it as a process whereby one tries to worm one's way into the other's inner realm; nor, for that matter, did they conceive of it as some kind of bridge-building between two essentially closed-off interiorities. On the contrary, and this is highlighted by both Stein and Husserl, when I empathically understand the other, the other is not given to me as a pure nucleus of experience, but as a center of intentionality, that is, as a different perspective on the very world that I also inhabit (Husserl 1973a: 140, 287, 1952: 168, Stein 1989: 61-62). Rather than facing the other as an isolated object, her intentionality will pull me along and make me co-attend her worldly objects. As Merleau-Ponty would later put it, "[m]y gaze falls upon a living body performing an action and the objects that surround it immediately receive a new layer of signification: they are no longer merely what I could do with them, they are also what this behavior is about to do with them" (2012:369).

It is important to defend a phenomenological account of empathy against some of the standard objections and, although beyond the scope of this paper (but see Zahavi 2014), it would also be imperative to investigate to what extent the phenomenological account might contain insights of relevance for the contemporary discussion of social cognition. But eventually one also has to realize the limitations of such an account. Consider that, on a standard reading, intersubjectivity is a relation between subjects; it is a subject-subject relation. But for me to relate to another as a subject is for me to relate to somebody with a first-person perspective of his or her own. We encounter others as such when we encounter them as experiencing subjects, namely as subjects that have a perspective not just upon the world of objects, but upon us as well. The problem, though, is that empathy can be one-sided: it can take place without any reciprocation. I can empathize with you, without your being aware of it. That certainly does seem to miss something quite crucial about the self-other relation. To quote Chris Frith:

Communication, when we confront each other face-to-face, is not a one-way process from me to you. The way you respond to me alters the way I respond to you. This is a communication loop. [...] This is the big difference from my interactions with the physical world. The physical world is utterly indifferent to my attempts to interpret it. But when two people interact face-to-face, their exchange of meaning is a cooperative venture. The flow is never just one-way (Frith 2007: 175).

We consequently ought to recognize that there is more to a satisfactory account of intersubjectivity and social life than what can be addressed through a phenomenological analysis of empathy. But, again, this is something that virtually all phenomenologists have recognized (see Zahavi 2001).

\section{Reciprocal empathy and the we}


Let us return to the contrast between the experiential self and the normatively enriched and narratively extended self. We are dealing with two notions placed at each end of the scale. On the one hand, we have a minimal take on the self that seeks to cash it out in terms of the first-person perspective. On the other hand, we have a far richer normatively guided notion that firmly situates the self in culture and history. Whereas the former notion captures an important but pre-social aspect of our experiential life, the latter notion most certainly does include the social dimension, but it does so by emphasizing the role of language. Given the difference between the two notions, it is natural to wonder about the developmental trajectory. How do we get from one to the other? A possible answer, that simultaneously suggests that the two notions are in need of a supplement, is to point to pre-linguistic forms of sociality with a direct impact on the formation and development of the self.

Much has been written about the importance of pre-linguistic forms of joint attention, i.e., those forms of social interaction where the infant and the adult are jointly attending to something. Ordinarily, it is claimed that infants start becoming aware of the other's attention when they are around 9-12 months of age. However, as Reddy has argued, when exemplifying forms of joint attention and social referencing, there has been a tendency to focus on triangulations that involve an object spatially separated from both adult and infant. But one might thereby overlook various other forms of joint attention, including those where the object of the joint attention is other people, objects close to our bodies, objects that are part of our bodies or, simply and most centrally, those situations where the object of the other's attention is the infant him- or herself (Reddy 2008: 97-98). As Reddy argues, if infants only started to become aware of the other's attention around the end of the first year of life, why should they then engage in complex face-to-face exchanges with others much earlier, namely from 2-3 months of age (Reddy 2008, 91)? According to Reddy, infants are aware of the other's attention initially and in the first instance when it is directed at themselves - she takes this to be the most powerful experience of attention that any of us will ever have (Reddy 2008: 92, 98). On her view, infants consequently exhibit an expanding awareness of the other's attention from around 2-3 months of age. They respond to the other's attention with interest, pleasure or distress, they call attention to themselves by making utterances, and they seem to expect people to work actively with them in order to sustain and regulate face-to-face interaction.

Although there is still some disagreement about how early the infant is able to be aware of itself as the object of the other's attention, there is widespread consensus that this understanding is manifest in a whole range of emotions. The presence of emotions such as shyness, coyness and embarrassment indicates that the infant has a sense of herself as the object of the other's evaluation, and that that evaluation matters to her (Tomasello 2001: 90, Hobson 2002: 82). Although emotions like these are often called self-conscious emotions, Reddy has suggested that it might ultimately be better to call them selfother-conscious emotions, since they make us aware of a relational being, that is, they all concern the self-in-relation-to-the-other (Reddy 2008: 145). In their developmentally primary form, these are emotions that reveal the exposed and interpersonal nature of the self (Reddy 2008: 126-7, 137, 143, 203).

Such a view is not philosophically unprecedented. 1) Mead famously argued that the problem of selfhood is the problem of how an individual can get experientially outside herself in such a way as to become an object to itself. Thus, for Mead, to be a self is ultimately more a question of becoming an 
object than of being a subject. In his view, one can only become an object to oneself in an indirect manner, namely by adopting the attitudes of others to oneself, and this is something that can only happen within a social environment (Mead 1962: 138). 2) In the third part of L'être et le néant, we find Sartre's famous analysis of shame. There, Sartre speaks of the existential alienation occasioned by my encounter with the other. To apprehend myself from the perspective of the other is to apprehend myself as seen in the midst of the world, as a thing among things, with properties and determinations that I have without having chosen them. The gaze of the other thrusts me into worldly space and time. I am no longer given to myself as the temporal and spatial center of the world. I am no longer simply "here" but, rather, next to the door, or on the couch; I am no longer simply "now", but too late for the appointment (Sartre 2003: 287, 291, 451, 544). 3) Likewise, Husserl calls attention to a special form of self-consciousness, namely the one where I experience the other as experiencing myself. Husserl describes this situation as involving a kind of iterative or higher-order empathy, and claims that my realization that I can be given for the other in the same way as the other is given for me leads to an important transformation in my selfapprehension. It is through this process of other-mediated self-experience, whereby I indirectly experience myself as one viewed by others, that I, for instance, come to experience myself as human (Husserl 1952: 167-9, 1959: 136-137, 1973b: 13, 665). Mead, Sartre and Husserl do not agree on everything, of course, but they all seem to recognize how important our adoption of the other's attitude towards ourselves is for our development as selves.

Let me propose that our experience of and subsequent adoption of the other's attitude towards ourselves, i.e., our coming to understand ourselves through others, contributes to the constitution of a new dimension of selfhood, one that brings us beyond the experiential self, while not yet amounting to a full-blown narratively extended self. Following Neisser, we might call this dimension the interpersonal self, i.e., the self in its relation to and interaction with others (Neisser 1991: 203-204). We develop as interpersonal selves, not only by experiencing ourselves in our interaction with and emotional response to others, but also by experiencing and internalizing the other's perspective on ourselves. The interpersonal self has clear presuppositions of its own, including the possession of a first-person perspective and a capacity for empathy. But it also feeds into the subsequent development of a more normatively enriched and diachronically extended narrative self, and can thereby serve as an important bridge between the two previously discussed dimensions of self. Might it also allow for new (and more reciprocal) forms of sociality? Can it, for instance, help us understand the emergence of weintentionality?

From the perspective of phenomenology, the we is not some entity that is observed from without but, rather, a distinct way of being with and relating to others: it is something I experience from within in virtue of my membership and participation in a particular community. One might by birth(right) be a member of a certain group (family, class, nation, ethnicity, etc.) regardless of whether one knows or cares about it, just as outsiders might classify one as a member of a certain group quite independently of one's own view on the matter. But this kind of group membership doesn't amount to a we. For a we to emerge, the prospective members have to identify with the group. It is their attitudes towards each other (and towards themselves) that are important (Carr 1986: 161). Saying this is by no means to say that the 
identification with and participation in the we always happens voluntarily. The point is merely that it in important ways involves rather than bypasses the self-understanding and first-person perspective of the involved parties.

To enjoy a we-experience, say, a shared feeling of joy, is to experience the other as participating with me in that experience. Thus, the joy is no longer simply experienced by me as mine, but as ours. This is why it makes perfect sense to articulate the experience in question with the use of the pronoun "we", as in "we enjoyed the movie together". But what kind of relation has to obtain between self and other in order to allow for the emergence of a we? Let me suggest that the we that emerges in face-toface interaction involves a distinct kind of reciprocity, one that requires the ability to adopt what has been termed a 'second-person perspective.' This is not an idea that is foreign to classical phenomenology. Consider the following quote by Schutz:

I take up an Other-orientation toward my partner, who is in turn oriented toward me. Immediately, and at the same time, I grasp the fact that he, on his part, is aware of my attention to him. In such cases I, you, we, live in the social relationship itself, and that is true in virtue of the intentionality of the living Acts directed toward the partner. I, you, we, are by this means carried from one moment to the next in a particular attentional modification of the state of being mutually oriented to each other. The social relationship in which we live is constituted, therefore, by means of the attentional modification undergone by my Other-orientation, as I immediately and directly grasp within the latter the very living reality of the partner as one who is in turn oriented toward me (Schutz 1967: 156-157).

To obtain a better understanding of the we, it might consequently be necessary to take a closer look at the you; a study of the second-person singular might be crucial for an understanding of the first-person plural (cf. Zahavi 2014 and 2015). To adopt the second-person perspective is to engage in a subjectsubject (you-me) relation, where the unique feature of relating to you as you is that you also have a second-person perspective on me, i.e., you take me as your you. To that extent, there cannot be a single you: there always has to be at least two. In short, to adopt the second-person perspective is for me to be aware of the other and, at the same time, to be implicitly aware of myself in the accusative, as attended to or addressed by the other (Husserl 1973a: 211).

To adopt the second-person perspective and to stand in a you-relation to somebody else is at the same time to modify and enrich your own self-experience. But this is precisely one of the requirements. The we-experience requires a preservation of plurality and a certain self-other differentiation but, if the difference between self and other is too salient, it will prevent any experience of togetherness. What is needed is the right balance between difference and similarity. This is why you cannot make do with your own ordinary, but exclusive, first-personal self-experience, if you are to join and participate in a weexperience. What you also need is a certain amount of self-alienation - to decrease your distance from, and make you more like, the others. You need to experience the others' perspectives on you, you need to be aware of them as being aware of you and to see yourself through their eyes, so that you can come to 
experience yourself in the same manner as you experience them. When that happens, you can become aware of yourself as one of them or, rather and more accurately, you can become aware of yourself as one of us. It is this process that Husserl is describing when he in Ideen II writes that I come to fit myself into the family of man, and create the possibility for the unity of this family, when I comprehend others as apprehending me in the same way as I apprehend them. And, as he then argues, it is only then that I am, for the first time and in the proper sense, an I over against an other and, thereby, in a position to say 'we' (Husserl 1952: 242, 250). Although Husserl's description of the process might make it sound overly complicated, it is not obvious that we are dealing with a process that only occurs late in development. Or, to put it differently, we shouldn't forget that the most advanced form of second-person perspective taking has developmental precursors. Over the years, Peter Hobson has argued that the process of "identifying-with" plays a very early and pivotal role in human development by structuring "social experience with polarities of self-other differentiation as well as connectedness" (Hobson 2008: 386). In a co-authored paper, the process in question is further described as follows: "to identify with someone else is to relate to the actions and attitudes of someone else from the other's perspective or stance, in such a way that a person assimilates the other's orientation toward the world, including toward the self, so that this orientation becomes a feature of the person's own psychological repertoire" (Hobson and Hobson 2007: 415). Importantly, Hobson also considers identifying-with to be crucially involved in affective sharing, and he argues that young infants' affective engagement with others already provides them with interpersonal experiences that encompass an interplay between similarity and difference, connectedness and differentiation (Hobson 2007: 270, cf. Reddy 2008).

Hans-Bernhard Schmid has recently denied that the we is founded upon an other-experience or in any other way involves or presupposes some kind of reciprocal relation between I and thou, ego or other. On his account, that which is shared, that which belongs to us, precedes the distinction between yours and mine and is prior to any form of intersubjectivity or mutual recognition (Schmid 2005: 145, 149, 296).

The contrast to the present proposal should be obvious. On the account I am proposing, the weexperience is not prior to or equiprimordial with self-experience or other-experience. Rather, paradigmatic cases of we-intentionality presuppose (without being reducible to) second-person perspective taking and reciprocal empathy. Self-other differentiation, the distinction between self and other, consequently precedes the emergence of, and is retained in, the we.

The we that emerges in and through concrete embodied face-to-face interaction might be developmentally and ontologically primary, but it is admittedly only one - rather ephemeral - type of we that is bound to the here and now. Far more institutionalized, anonymous and linguistically mediated forms of we also exist. Further investigations are needed in order to lay bare the processes involved in the constitution of more stable we-identities.

I would agree with those who claim that results from the domains of social cognition and social ontology can put pressure on certain basic assumptions in the philosophy of mind. Findings in the former domains might force us to revise or even reject certain overly solipsistic and disembodied accounts of mind and self if the latter should turn out to be incompatible with the existence of genuine we- 
phenomena. I agree with this, but I would also reject the proposal that the way forward, when it comes to developing a satisfactory account of the we, is to altogether jettison notions such as subject, subjectivity, I, you, me, self, and other. To do that would not only be to throw out the proverbial baby with the bathwater, it would also suggest a commitment to the very Cartesian conception of the subject that one was allegedly trying to overcome.

\section{REFERENCES}

Carr, D. (1986). Time, Narrative, and History. Bloomington: Indiana University Press.

Cassirer, E. (1957). The Philosophy of Symbolic Forms III. New Haven: Yale University Press.

Cialdini, R. B., Brown, S. L., Lewis, B. P., Luce, C., \& Neuberg, S. L. (1997). Reinterpreting the empathy-altruism relationship: when one into one equals oneness. Journal of Personality and Social Psychology, 73(3), 481-494.

Dennett, D. (1987). The Intentional Stance. Cambridge, MA: MIT Press.

Dretske, F. (1995). Naturalizing the Mind. Cambridge, MA: MIT Press.

Dretske, F. (2003). How Do You Know You Are Not a Zombie? In B. Gertler (Ed.), Privileged Access: Philosophical Accounts of Self-Knowledge (pp. 1-13). Aldershot: Ashgate.

Fink, C. K. (2012). The 'Scent' of a Self: Buddhism and the First-Person Perspective. Asian Philosophy, 22(3), 289-306.

Frith, C. (2007). Making up the Mind: How the Brain Creates Our Mental Worlds. Oxford: WileyBlackwell.

Gurwitsch, A. (1979). Human Encounters in the Social World. Pittsburgh: Duquesne University Press.

Heidegger, M. (2001). Einleitung in die Philosophie. Gesamtausgabe Band 27. Frankfurt am Main: Vittorio Klostermann.

Henry, M. (1963). L'essence de la manifestation. Paris: PUF.

Hobson, R. P. (2002). The Cradle of Thought. London: Macmillan.

Hobson, R.P. (2007). Communicative Depth: Soundings from Developmental Psychopathology. Infant Behavior \& Development 30, 267-277.

Hobson, R.P. (2008). Interpersonally Situated Cognition. International Journal of Philosophical Studies 16(3), 377-397.

Hobson, J. A., \& Hobson, R.P. (2007). Identification: The Missing Link between Joint Attention and Imitation? Development and Psychopathology 19, 411-431.

Husserl, E. (1950). Cartesianische Meditationen und Pariser Vorträge. Ed. S. Strasser. Husserliana 1. Den Haag: Martinus Nijhoff.

Husserl, E. (1952). Ideen zu einer reinen Phänomenologie und phänomenologischen Philosophie. Zweites Buch. Phänomenologische Untersuchungen zur Konstitution. E. M. Biemel. Husserliana 4. Den Haag: Martinus Nijhoff.

Husserl, E. (1959). Erste Philosophie (1923/24). Zweiter Teil. Theorie der phänomenologischen 
Reduktion. Ed. R. Boehm. Husserliana 8. Den Haag: Martinus Nijhoff.

Husserl, E. (1973a). Zur Phänomenologie der Intersubjektivität II. Texte aus dem Nachlass. Zweiter Teil. 1921-28. Ed. I. Kern. Husserliana 14. Den Haag: Martinus Nijhoff.

Husserl, E. (1973b). Zur Phänomenologie der Intersubjektivität III. Texte aus dem Nachlass. Dritter Teil. 1929-35. Ed. I. Kern. Husserliana 15. Den Haag: Martinus Nijhoff.

Husserl, E. (1976). Ideen zu einer reinen Phänomenologie und phänomenologischen Philosophie. Erstes Buch: Allgemeine Einführung in die reine Phänomenologie. Ed. K. Schuhmann. Husserliana 3, 1-2. Den Haag: Martinus Nijhoff.

Korsgaard, C. M. (2009). Self-Constitution: Agency, Identity, and Integrity. Oxford: Oxford University Press.

Maclaren, K. (2008). Embodied Perceptions of Others as a Condition of Selfhood: Empirical and Phenomenological Considerations. Journal of Consciousness Studies, 15(8), 63-93.

Mead, G. H. (1962). Mind, Self and Society: From the Standpoint of a Social Behaviorist. Chicago: University of Chicago Press.

Meltzoff, A. N., \& Moore, M. K. (1995). A Theory of the Role of Imitation in the Emergence of Self. In P. Rochat (Ed.), The Self in Infancy: Theory and Research (pp. 73-93). Amsterdam: Elsevier.

Merleau-Ponty, M. (2012). Phenomenology of Perception. Trans. D. A. Landes. London: Routledge.

Metzinger, T. (2003). Being No One. Cambridge, MA: MIT Press.

Metzinger, T. (2011). The No-Self Alternative. In S. Gallagher (Ed.), The Oxford Handbook of the Self (pp. 279-296). Oxford: Oxford University Press.

Neisser, U. (1991). Two Perceptually Given Aspects of the Self and Their Development. Developmental Review, 11(3), 197-209.

Prinz, W. (2003). Emerging Selves: Representational Foundations of Subjectivity. Consciousness and Cognition, 12(4), 515-528.

Prinz, W. (2012). Open Minds: The Social Making of Agency and Intentionality. Cambridge, MA: MIT Press.

Reddy, V. (2008). How Infants Know Minds. Cambridge, Mass.: Harvard University Press.

Rudd, A. (2012). Self, Value, \& Narrative: A Kierkegaardian Approach. Oxford University Press.

Sartre, J.-P. (2003). Being and Nothingness: An Essay in Phenomenological Ontology. Trans. H. E. Barnes. London and New York: Routledge.

Schechtman, M. (2011). The Narrative Self. In S. Gallagher (Ed.), The Oxford Handbook of the Self (pp. 394-418). Oxford University Press.

Scheler, M. (2008). The Nature of Sympathy. London: Transaction Publishers.

Schmid, H. B. (2005). Wir-Intentionalität: Kritik des ontologischen Individualismus und Rekonstruktion der Gemeinschaft. Freiburg: Karl Alber.

Schutz, A. (1967). Phenomenology of the Social World. Evanston, IL: Northwestern University Press.

Stein, E. (1989). On the Problem of Empathy, trans. W. Stein. Washington, DC: ICS.

Taylor, C. (1989). Sources of the Self. Cambridge, MA: Harvard University Press.

Tomasello, M. (2001). The Cultural Origins of Human Cognition. Cambridge, MA: Harvard University 
Press.

Zahavi, D. (2001). Beyond Empathy. Phenomenological Approaches to Intersubjectivity. Journal of Consciousness Studies, 8(5-7), 151-167.

Zahavi, D. (2005). Subjectivity and Selfhood: Investigating the First-Person Perspective. Cambridge, MA: The MIT Press.

Zahavi, D. (2009). Is the self a social construct? Inquiry, 52/6, 551-573

Zahavi, D. (2010). Empathy, Embodiment and Interpersonal Understanding: From Lipps to Schutz. Inquiry, 53(3), 285-306.

Zahavi, D. (2011). Empathy and Direct Social Perception: A Phenomenological Proposal. Review of Philosophy and Psychology, 2(3), 541-558.

Zahavi, D. (2012). Empathy and mirroring: Husserl and Gallese. In R. Breeur \& U. Melle (eds.): Life, Subjectivity \& Art: Essays in Honor of Rudolf Bernet (pp. 217-254). Dordrecht: Springer.

Zahavi, D. (2014). Self and Other: Exploring Subjectivity, Empathy, and Shame. Oxford: Oxford University Press.

Zahavi, D. (2015). You, me and we: The sharing of emotional experiences. Journal of Consciousness Studies, 22(1-2), 84-101. 